Gynäkologische Endokrinologie 2012 · 10:225-226 DOI 10.1007/s10304-012-0476-8

Online publiziert: 17. Oktober 2012

c) Springer-Verlag Berlin Heidelberg 2012

R. Felberbaum ${ }^{1} \cdot$ W. Küpker ${ }^{2}$

${ }^{1}$ Frauenklinik, Klinikum Kempten Oberallgäu gGmbH, Kempten

${ }^{2}$ Endometriosezentrum, Stadtklinik Baden-Baden, Baden-Baden

\title{
Stammzellforschung und Reproduktionsmedizin
}

\section{So nah und doch so fern!}

Als 1998 die Arbeitsgruppe um Thomson u. Itskovitz-Eldor [1] in Science über die Etablierung stabiler Linien humaner embryonaler Stammzellen (hES-Zellen) berichtete, war das Echo groß. Einerseits schienen die Tore für eine alle Verheißungen erfüllende regenerative Medizin weit geöffnet, andererseits aber hatte die humane Reproduktionsmedizin wohl ihre Unschuld endgültig verloren. Humane Embryonen waren zerstört worden, um ihre Stammzellen anderen als reproduktiven Zwecken zuzuführen. Dieses Dilemma konnte und kann bis heute nicht aufgelöst werden.

Das Deutsche Gesetz zur Sicherstellung des Embryonenschutzes im Zusammenhang mit Einfuhr und Verwendung menschlicher embryonaler Stammzellen von 2002 verbot zwar prinzipiell die Einfuhr und Verwendung embryonaler Stammzellen in Deutschland, ließ aber unter Erfüllung bestimmter Voraussetzungen die Einfuhr solcher Zellen für Forschungszwecke in der Grundlagenforschung zu.

Nach nun über 10 Jahren intensiver Forschung ist ein großer Erkenntnisgewinn auf einer Vielzahl von Forschungsgebieten zu erkennen. Die übersteigerten Hoffnungen auf einen Einsatz im Rahmen der regenerativen Medizin erfüllten sich bisher aber nicht. So sind von der US-amerikanischen Food and Drug Administration (FDA) bislang nur 2 Studien an Patienten zugelassen worden. In einer Studie wurden aus hES-Zellen abgeleitete oligodendritische Vorläuferzellen transplantiert, in der anderen aus hES-Zellen abgeleitete pigmentierte Epithelzellen der Retina. Vor allem letztere Arbeit zeigte bisher vielversprechende Ergebnisse [2].

Die 2007 von Takahashi et al. [3] erstmals publizierten Daten zur Generierung von reprogrammierten somatischen Zellen, also humanen induzierten pluripotenten Stammzellen (hiPS-Zellen), schien das Problem des ethischen Konflikts zu lösen. Zumindest wurde es, auch von politischer Seite, gerne so dargestellt. Allerdings ist noch nicht geklärt, inwieweit die Eigenschaften der hiPS-Zellen mit denen der hES-Zellen deckungsgleich sind, sodass die Verwendung der letzteren auf lange Zeit unverzichtbar bleiben wird.

Die Tatsache, dass es gelungen ist, aus murinen embryonalen Stammzellen befruchtungsfähige Gameten abzuleiten, erlaubt zumindest die Frage, ob dies auch bei hES- oder hiPS-Zellen möglich sein könnte [4]. Diese Frage ist bisher nicht beantwortet. Dennoch macht es Sinn, sich bereits jetzt mit den ethischen Implikationen solcher rekonstruierter Gameten und Embryonen zu beschäftigen, die in der Zukunft zur Verfügung stehen könnten. Zumindest gelingt es bereits, aus hESund hiPS-Zellen Vorläufer der Keimzellen ["primordial germ cells" (PGC)] abzuleiten [5]. Die Vorstellung, aus hiPS-Zellen patientenspezifische Gameten für die In-vitro-Fertilisation zu gewinnen, ist zu bezwingend, um sie als blanken Unsinn abzutun. Man denke nur an die Urteile der wissenschaftlichen und nichtwissenschaftlichen Gesellschaft über die Arbeit der Pioniere der assistierten Reproduktion vor der Geburt von Loise Brown.

\section{Auch die Forschung an adulten Stammzellen scheint neue Wege in der Reproduktionsmedizin zu eröffnen.}

Neue Erkenntnisse zur Pathogenese der Endometriose als stammzellbasierte Erkrankung könnten neue Strategien in der Therapie initiieren. Ebenso scheint die Kultur und Retransplantation menschlicher männlicher Keimstammzellen eine Neubesiedlung des Hodens onkologischer Patienten nach Chemotherapie zu ermöglichen. Dies wäre ein völlig neuer fertilitätserhaltender Ansatz beim Mann.

Die Ergebnisse der Arbeitsgruppe um Tilly [6], der es gelungen ist, menschliche weibliche Keimstammzellen ["oogonial stem cells" (OSC)] zu isolieren und zu kultivieren, müssen als bahnbrechend bezeichnet werden. Das Dogma, dass eine Regeneration des Eizellpools nach der Geburt nicht mehr stattfindet, ist damit gefallen. Aber auch hier wird noch viel Zeit vergehen, bis diese OSC für reproduktive Zwecke beim Menschen eingesetzt werden können. Wer hat jedoch 1978 geglaubt, dass die In-vitro-Fertilisation sich fest im Kanon der Therapiemodalitäten verankern würde?

Um eine solche Entwicklung zu ermöglichen sind grundlegende Arbeiten an Kulturmedien und einer strukturschaffenden Matrix notwendig. Diese müssen frei von tierischen und möglicherweise kontaminierenden Elementen sein. Gerade hieran wird im asiatischen Raum intensiv geforscht. Die Entdeckung spontan zu Hydrogelen aggregierender sehr 


\section{Einführung zum Thema}

kleiner Peptide könnte in diesem Zusammenhang ein wesentlicher Entwicklungsschritt sein.

Die Wahrscheinlichkeit, dass wir den klinischen Einsatz aus Stammzellen abgeleiteter Gameten in der Reproduktionsmedizin nicht mehr erleben werden, ist sicher groß. Aber der Weg ist das Ziel.

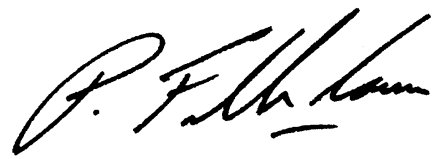

Prof. Dr. Ricardo Felberbaum

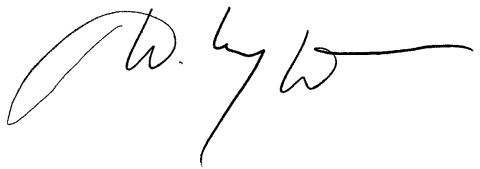

Prof. Dr. Wolfgang Küpker

\section{Korrespondenzadresse}

\section{Prof. Dr. R. Felberbaum}

Frauenklinik, Klinikum Kempten

Oberallgäu gGmbH

Robert-Wexler-Str. 50, 87439 Kempten

ricardo.felberbaum@klinikum-kempten.de

\section{Literatur}

1. Thomson JA, Itskovitz-Eldor J, Shapiro SS et al (1998) Embryonic stem cell lines derived from human blastocysts. Science 282:1145-1147

2. Schwartz SD, Hubschman JP, Heilwell G et al (2012): Embryonic stem cell trials for macular degeneration: a preliminary report. Lancet 379:713720

3. Takahashi K, Tanabe K, Ohnuki M et al (2007) Induction of pluripotent stem cells from adult human fibroblasts by defined factors. Cell 131:861872

4. Hübner K, Fuhrmann G, Christenson LK et al (2003) Derivation of oocytes from mouse embryonic stem cells. Science 300:1251-1256

5. Nicholas CR, Chavez SL, Baker VL, Reijo Pera RA (2009) Instructing an embryonic stem cell-derived oocyte fate: lessons from endogenous oogenesis. Endocrinol Rev 30:264-283

6. Woods DC, Tilly JL (2012) The next (re)generation of ovarian biology and fertility in women: is current science tomorrow's practice? Fertil Steril 98:310

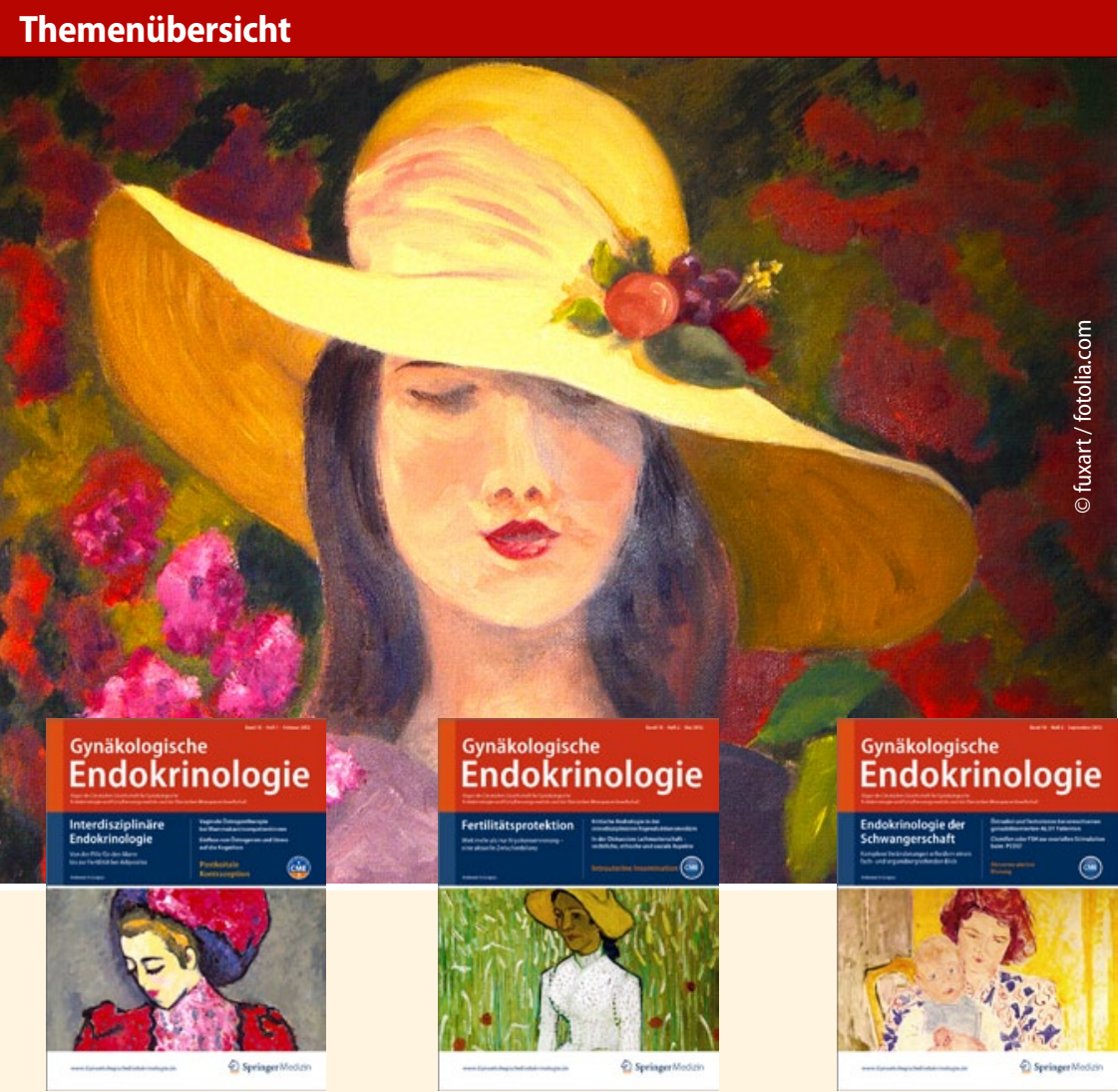

Die Gynäkologische Endokrinologie bietet Ihnen umfassende und aktuelle Beiträge zu interessanten Themenschwerpunkten aus allen Bereichen der gynäkologischen Endokrinologie. Möchten Sie ein bereits erschienenes Heft nachbestellen? Einzelne Ausgaben können Sie direkt bei unserem Kundenservice zum Preis von je EUR 34,- zzgl. Versandkosten beziehen:

2011

1/11 Hormone und Psyche

2/11 Differenzialdiagnostik u. Therapieoptionen der Hyperandrogämie

3/11 Menopause und Frauengesundheit

4/11 Reproduktionsmedizin

\section{2}

1/12 Gynäkologische/Internistische Endokrinologie

2/12 Fertilität in der Onkologie

3/12 Endokrinologie der Schwangerschaft

4/12 Stammzellforschung und Reproduktionsmedizin

\section{Vorschau 2013}

1/13 Gynäkologische Endokrinologie in der Kinder- und Jugendzeit

2/13 Habituelle Aborte

3/13 Hormonale Kontrazeption

4/13 Geriatrische Endokrinologie

So erreichen Sie unseren Kundenservice:

Springer Customer Service Center GmbH

Kundenservice Zeitschriften

Haberstr. 7

69126 Heidelberg

Tel.: + $496221345-4303$

Fax: +496221 345-4229

E-Mail: leserservice@springer.com

\section{www.GynaekologischeEndokrinologie.de}

